\title{
INFLUENCE OF MACHINING TECHNOLOGIES ON VALUES OF RESIDUAL STRESSES OF OXIDE CUTTING CERAMICS
}

\author{
Jakub NĚmeČEK*， KAmil KolaříK, JiŘí ČAPEK, Nikolaj GaneV \\ Department of Solid State Engineering, Faculty of Nuclear Science and Physical Engineering, Czech Technical \\ University in Prague \\ * corresponding author: j.nemecek91@gmail.com
}

\begin{abstract}
Currently, the intensive development of engineering ceramic and effort to replace sintered carbides as cutting materials are in progress. With the development of the sintering technology it is now possible to produce compact ceramic cutting samples with very good mechanical properties. The advantage of these materials is their easy accessibility and low purchase price. In this work, the influence of the finishing machine technology on the values of surface residual stresses of cutting ceramic samples $\mathrm{Al}_{2} \mathrm{O}_{3}+\mathrm{TiC}$ were studying. The samples were supplied by Moscow State University of Technology STANKIN. Measurements made in the X-ray diffraction laboratory at the Department of solid state engineering were performed for both the phases. The influence of the parameters of machining to residual stresses was studied and the resulting values were compared with each other.
\end{abstract}

KeYwords: Cutting ceramic; Machining technology; X-Ray diffraction; Residual stresses.

\section{INTRODUCTION}

Ceramic tools have been used since the Stone Age, when sandstone containing large amounts of silica blades was used, for example for the sharpening of knives, razor blades or other tools. This material was used henceforward as abrasive wheels during the ages of cutting weapons for sharpening of swords, knives and other blades. Only recently these grinding tools have been replaced by other modern materials for example by $\mathrm{SiC}$ or diamond.

At the beginning of the 20th century, the first use of $\mathrm{Al}_{2} \mathrm{O}_{3}$ ceramics as a cutting tool occurred. Over the years, its development had moved to a level at which we were able to replace, for example, sintered carbides using those ceramic materials. This effort has been caused by the mechanical properties of aluminium oxide and the easy availability of the starting materials [1, 2].

The aim of this paper is to study the real structure of $\mathrm{Al}_{2} \mathrm{O}_{3}+\mathrm{TiC}$ oxide cutting ceramic. The microstrains and a size of crystallites was measured and influence of machining technologies on the macroscopic residual stresses was studied.

\subsection{Preparation of Samples}

The starting materials and their properties have been known for a long time. The problem was how to make compact samples with the desired mechanical properties and dimensions. The current production process consists of three parts: first, grinding the starting material to a powder with grain size of the order of $100 \mathrm{~nm}$, second, sintering the powders into a compact form and third, the surface treatment of the samples to the desired dimensions.

An important technological aspect of the properties of cutting ceramics is the grain size of the starting pow- ders. If the individual grain size is approximately the same (if they have ideal spherical shape), the uniform distribution and the pore size are gained more easily during forming and thereby for uniform compaction throughout the volume and easier reorganization of the particles during sintering. Preference is also to achieve the smallest grain size of the sample, because it leads to faster material transport [3].

The sintering process is very similar to that used for sintered carbides. The powder is pressed below the melting point into a compact body, see Figure 1 But the main difference is the absence of a binder which during sintering formed a liquid phase, because it would cause degradation of mechanical properties. Today, ceramic is most commonly sintered into rods of cross section of finite samples and then cut to the desired dimensions. Individual plates are then variously surface treated and shaped [4].

\section{X-RAY DIFFRACTION ANALYSIS OF MACROSCOPIC RESIDUAL STRESSES}

In cooperation with the Moscow State Technological University STANKIN that provides manufacturing technology, the influence of machining technologies on the value of residual stresses in samples of $\mathrm{Al}_{2} \mathrm{O}_{3}+\mathrm{TiC}$ oxide cutting ceramics were investigated in X-ray diffraction laboratory of the Department of Solid State Engineering of FNSPE CTU in Prague. All experimental errors were around $10 \%$ of absolute value of measurement.

\subsection{GRINDING BY DIAMOND DISC}

After sintering, all samples were ground using a diamond wheel. An effect of displacement of the workpiece on the lift at constant cutting speed, feed rate 


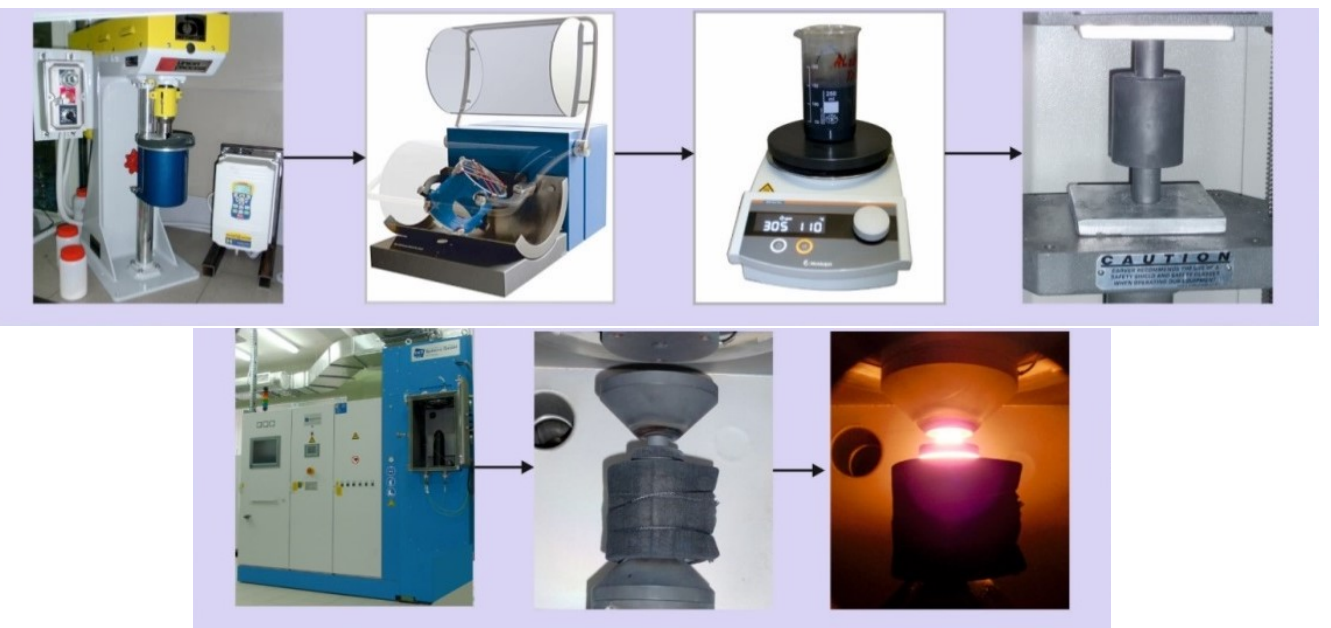

FiguRE 1. Scheme of creation technology of cutting ceramic sample: refinement powders (wet grinding), evaporation, pressing, sintering [5].

\begin{tabular}{ccc}
\hline Sample & $\begin{array}{c}\text { Fd, } \\
\text { displacement } \\
\text { on the lift } \\
{[\mathrm{mm} / \text { displ. }]}\end{array}$ & $\begin{array}{c}\text { ap, } \\
\text { depth of cut } \\
{[\mathrm{mm}]}\end{array}$ \\
\hline 1 & 0.5 & 0.04 \\
2 & 1.0 & 0.04 \\
3 & 1.5 & 0.04 \\
\hline
\end{tabular}

TABLE 1. Parameters of grinding by diamond disc.

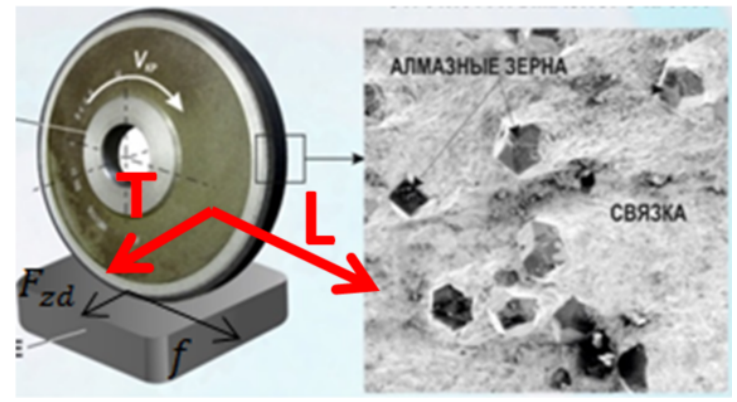

Figure 2. Scheme of grinding by diamond disc [5].

of the workpiece in the cutting direction and depth of cut was observed. Grinding parameters are given in Table 1. where cutting speed $V_{c}=30 \mathrm{~m} / \mathrm{s}$ and feed rate $f=12 \mathrm{~m} / \mathrm{min}$.

Values of residual stresses were determined in two orthogonal directions L (direction of the grinding wheel) and $\mathrm{T}$ (direction of displacement on the lift). Because of unidirectional grinding anisotropy of values was observed in both directions. Different values are due to the different structure of $\mathrm{Al}_{2} \mathrm{O}_{3}$ (trigonal) and $\mathrm{TiC}$ (cubic) and the different number of slip planes (see Table 2).

\subsection{Thermal ANNEALING OF THE SAMPLES AFTER GRINDING BY DIAMOND DISC}

Next samples were ground by diamond disc with the same machining parameters and then thermally an-
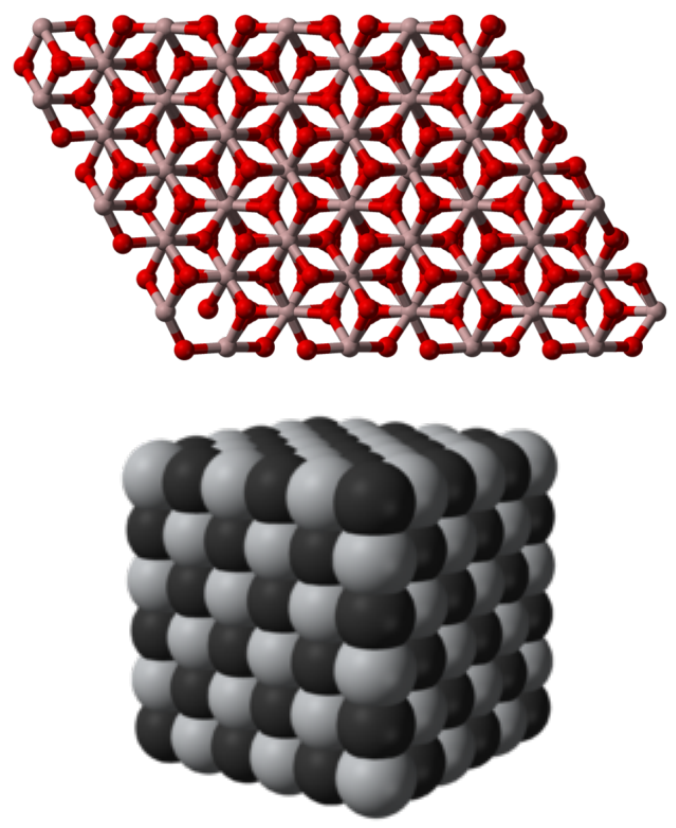

Figure 3. Structure of $\mathrm{Al}_{2} \mathrm{O}_{3}$ (up) and TiC (down).

nealed at $800{ }^{\circ} \mathrm{C}$. It is evident from Table 3 that the values of the macroscopic residual stresses decreased considerably. In contrast, the value of microstrains and grain size given by the parameter FWHM remained almost unchanged.

\subsection{Air Abrasive Machining}

In this method of machining, air of high pressure with added cutting microparticles is jetted on a rotating sample. The effect of air pressure changes on the residual stress in the sample was studied (Table 4) with constant time of blasting $T=60 \mathrm{~s}$ and rotates per minute $R P M=50$.

The obtained values (Table 5) show that when a pressure increases from 2 to 2.5 bars a decrease of compressive residual stresses (stress relaxation) is ob- 


\begin{tabular}{|c|c|c|c|c|c|c|c|}
\hline \multicolumn{4}{|c|}{$\mathrm{Al}_{2} \mathrm{O}_{3}$} & \multicolumn{4}{|c|}{$\mathrm{TiC}$} \\
\hline \multicolumn{4}{|c|}{ L direction $\mathrm{RS} \operatorname{Mn} K \alpha(0210)$} & \multicolumn{4}{|c|}{$\overline{\mathrm{L}}$ direction $\mathrm{RS} \operatorname{Cr} K \alpha(311)$} \\
\hline Sample & $\begin{array}{c}\sigma_{N} \\
{[\mathrm{MPa}]}\end{array}$ & $\begin{array}{c}\sigma_{S} \\
{[\mathrm{MPa}]}\end{array}$ & $\begin{array}{c}\text { FWHM } \\
{[2 \Theta]}\end{array}$ & Sample & $\begin{array}{c}\sigma_{N} \\
{[\mathrm{MPa}]}\end{array}$ & $\begin{array}{c}\sigma_{S} \\
{[\mathrm{MPa}]}\end{array}$ & $\begin{array}{c}\text { FWHM } \\
{[2 \Theta]}\end{array}$ \\
\hline 1 & -216 & 33 & 0.787 & 1 & -518 & 77 & 0.759 \\
\hline 2 & -182 & 39 & 0.693 & 2 & -536 & 77 & 0.741 \\
\hline 3 & -165 & 37 & 0.859 & 3 & -530 & 74 & 0.708 \\
\hline \multicolumn{4}{|c|}{$\mathrm{T}$ direction $\mathrm{RS} \operatorname{Mn} K \alpha(0210)$} & \multicolumn{4}{|c|}{$\mathrm{T}$ direction $\mathrm{RS} \operatorname{Cr} K \alpha(311)$} \\
\hline Sample & $\begin{array}{c}\sigma_{N} \\
{[\mathrm{MPa}]}\end{array}$ & $\begin{array}{c}\sigma_{S} \\
{[\mathrm{MPa}]}\end{array}$ & $\begin{array}{c}\text { FWHM } \\
{[2 \Theta]}\end{array}$ & Sample & $\begin{array}{c}\sigma_{N} \\
{[\mathrm{MPa}]}\end{array}$ & $\begin{array}{c}\sigma_{S} \\
{[\mathrm{MPa}]}\end{array}$ & $\begin{array}{c}\text { FWHM } \\
{[2 \Theta]}\end{array}$ \\
\hline 1 & -436 & 36 & 0.804 & 1 & -776 & 67 & 0.668 \\
\hline 2 & -470 & 30 & 0.709 & 2 & -805 & 93 & 0.759 \\
\hline 3 & -580 & 37 & 0.772 & 3 & -938 & 89 & 0.679 \\
\hline
\end{tabular}

TABLE 2. The values of normal $\left(\sigma_{N}\right)$ and shear $\left(\sigma_{S}\right)$ residual stresses after grinding by a diamond disc.

\begin{tabular}{|c|c|c|c|c|c|c|c|}
\hline \multicolumn{4}{|c|}{$\mathrm{Al}_{2} \mathrm{O}_{3}$} & \multicolumn{4}{|c|}{$\mathrm{TiC}$} \\
\hline \multicolumn{4}{|c|}{$\mathrm{L}$ direction $\mathrm{RS} \operatorname{Mn} K \alpha(0210)$} & \multicolumn{4}{|c|}{$\mathrm{L}$ direction $\mathrm{RS} \operatorname{Cr} K \alpha(311)$} \\
\hline Sample & $\begin{array}{c}\sigma_{N} \\
{[\mathrm{MPa}]}\end{array}$ & $\begin{array}{c}\sigma_{S} \\
{[\mathrm{MPa}]}\end{array}$ & $\begin{array}{c}\text { FWHM } \\
{[2 \Theta]}\end{array}$ & Sample & $\begin{array}{c}\sigma_{N} \\
{[\mathrm{MPa}]}\end{array}$ & $\begin{array}{c}\sigma_{S} \\
{[\mathrm{MPa}]}\end{array}$ & $\begin{array}{c}\text { FWHM } \\
{[2 \Theta]}\end{array}$ \\
\hline 12 & -185 & 19 & 0.666 & 12 & -516 & 91 & 0.965 \\
\hline 13 & -203 & 16 & 0.888 & 13 & -290 & 40 & 0.609 \\
\hline 14 & -199 & 30 & 0.889 & 14 & -289 & 112 & 0.847 \\
\hline \multicolumn{4}{|c|}{$\mathrm{T}$ direction $\mathrm{RS} \operatorname{Mn} K \alpha(0210)$} & \multicolumn{4}{|c|}{ T direction $\operatorname{RS} \operatorname{Cr} K \alpha(311)$} \\
\hline Sample & $\begin{array}{c}\sigma_{N} \\
{[\mathrm{MPa}]}\end{array}$ & $\begin{array}{c}\sigma_{S} \\
{[\mathrm{MPa}]}\end{array}$ & $\begin{array}{c}\text { FWHM } \\
{[2 \Theta]}\end{array}$ & Sample & $\begin{array}{c}\sigma_{N} \\
{[\mathrm{MPa}]}\end{array}$ & $\begin{array}{c}\sigma_{S} \\
{[\mathrm{MPa}]}\end{array}$ & $\begin{array}{c}\text { FWHM } \\
{[2 \Theta]}\end{array}$ \\
\hline 12 & -303 & 20 & 0.781 & 12 & -599 & 71 & 0.782 \\
\hline 13 & -359 & 6 & 0.802 & 13 & -474 & 57 & 0.613 \\
\hline 14 & -342 & 27 & 0.769 & 14 & -473 & 104 & 0.908 \\
\hline
\end{tabular}

TABLE 3 . The values of normal $\left(\sigma_{N}\right)$ and shear $\left(\sigma_{S}\right)$ residual stresses after thermal annealing.

\begin{tabular}{cc}
\hline Sample & $\begin{array}{c}\text { P, } \\
\text { air pressure } \\
{[\mathrm{MPa}]}\end{array}$ \\
\hline 4 & 1.5 \\
5 & 2.0 \\
6 & 2.5 \\
\hline
\end{tabular}

TABLE 4. Parameters of air abrasive machining.


FiguRE 4. Scheme of air abrasive machining and a picture of machining chamber [5].

served. It is probably a result of overcoming the yield strength of the material. Perhaps machining process with higher pressure values influences deeper sub-surface layers of material. The energy required for crack propagation is therefore higher for these seemingly lower pressure residual stresses. To confirm this assertion, a depth-profile analysis of residual stresses by sequential force-free etching of surface layers is needed.

Rotational movement of the specimen during the machining leads to an isotropic stress distribution i.e., the values in both the directions $\mathrm{L}$ and $\mathrm{T}$ are similar.

\subsection{WATER Jet MACHINING}

Water Jet Machining (WJM) is based on the same principle as air abrasive machining, when a focused beams of water is jetted out by varying the pressure on the rotating sample (see Figure 6 and Table 6). Other parameters: time of blasting $T=60 \mathrm{~s}$, distance of samples $L=2 \mathrm{~mm}$, number of nozzles $N=50$.

It is evident, that for applied values of pressure jetting the yield strength value have not been overcome. The values of residual compressive residual stresses increase steadily with increasing pressure in contrast to the samples after air abrasive machining. Due to the rotating of the samples an isotropic residual stress distribution is achieved again (see Table 7). 


\begin{tabular}{|c|c|c|c|c|c|c|c|}
\hline \multicolumn{4}{|c|}{$\mathrm{Al}_{2} \mathrm{O}_{3}$} & \multicolumn{4}{|c|}{$\mathrm{TiC}$} \\
\hline \multicolumn{4}{|c|}{$\mathrm{L}$ direction $\mathrm{RS} \operatorname{Mn} K \alpha(0210)$} & \multicolumn{4}{|c|}{ L direction $\mathrm{RS} \operatorname{Cr} K \alpha(311)$} \\
\hline Sample & $\begin{array}{c}\sigma_{N} \\
{[\mathrm{MPa}]}\end{array}$ & $\begin{array}{c}\sigma_{S} \\
{[\mathrm{MPa}]}\end{array}$ & $\begin{array}{c}\text { FWHM } \\
{[2 \Theta]}\end{array}$ & Sample & $\begin{array}{c}\sigma_{N} \\
{[\mathrm{MPa}]}\end{array}$ & $\begin{array}{c}\sigma_{S} \\
{[\mathrm{MPa}]}\end{array}$ & $\begin{array}{c}\text { FWHM } \\
{[2 \Theta]}\end{array}$ \\
\hline 4 & $\begin{array}{c}-352 \\
\end{array}$ & 34 & 0.787 & 4 & $\begin{array}{l}-799 \\
\end{array}$ & 117 & 0.965 \\
\hline 5 & -367 & 45 & 0.694 & 5 & -928 & 111 & 0.609 \\
\hline 6 & -242 & 32 & 0.827 & 6 & -278 & 83 & 0.847 \\
\hline \multicolumn{4}{|c|}{ T direction RS $\operatorname{Mn} K \alpha(0210)$} & \multicolumn{4}{|c|}{$\mathrm{T}$ direction $\mathrm{RS} \operatorname{Cr} K \alpha(311)$} \\
\hline Sample & $\begin{array}{c}\sigma_{N} \\
{[\mathrm{MPa}]}\end{array}$ & $\begin{array}{c}\sigma_{S} \\
{[\mathrm{MPa}]}\end{array}$ & $\begin{array}{c}\text { FWHM } \\
{[2 \Theta]}\end{array}$ & Sample & $\begin{array}{c}\sigma_{N} \\
{[\mathrm{MPa}]}\end{array}$ & $\begin{array}{c}\sigma_{S} \\
{[\mathrm{MPa}]}\end{array}$ & $\begin{array}{c}\text { FWHM } \\
{[2 \Theta]}\end{array}$ \\
\hline 4 & -295 & 42 & 0.781 & 4 & -737 & 119 & 0.641 \\
\hline 5 & -389 & 44 & 0.802 & 5 & -899 & 123 & 0.890 \\
\hline 6 & -284 & 36 & 0.769 & 6 & -283 & 69 & 0.611 \\
\hline
\end{tabular}

TABLE 5. The values of normal $\left(\sigma_{N}\right)$ and shear $\left(\sigma_{S}\right)$ residual stresses after air abrasive machining.

\begin{tabular}{cc}
\hline Sample & $\begin{array}{c}\text { P, } \\
\text { Pressure } \\
{[\mathrm{MPa}]}\end{array}$ \\
\hline 7 & 1.5 \\
8 & 2.0 \\
9 & 2.5 \\
\hline
\end{tabular}

TABle 6. Parameters of Water Jet Machining.

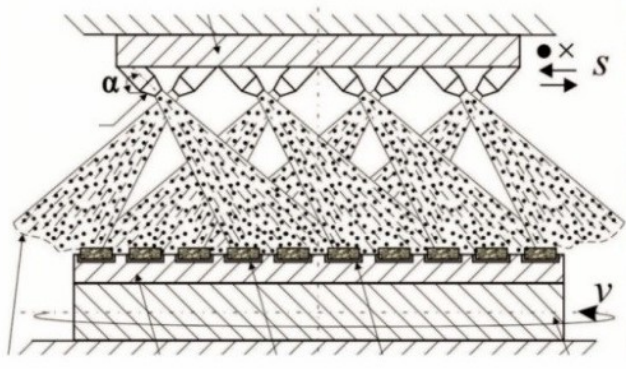

FiguRE 5. Scheme of Water Jet Machining.

\subsection{LASer Shock PeEning}

During machining by laser the samples are heated and it results in stress relaxation. Increased power (see Table 9 will lead to higher temperatures, and thus to higher stress relaxation. Furthermore, it is possible to observe the influence of the laying of individual spots (overlapping) on the anisotropy of distribution of residual stresses.

\subsection{Stress tests - The EFFECT OF FRICTION}

After grinding of samples by diamond disc their surface was loaded by rotating steel disk at different time intervals. The influence of time of friction on values of residual stresses was investigated (see table 10 ).

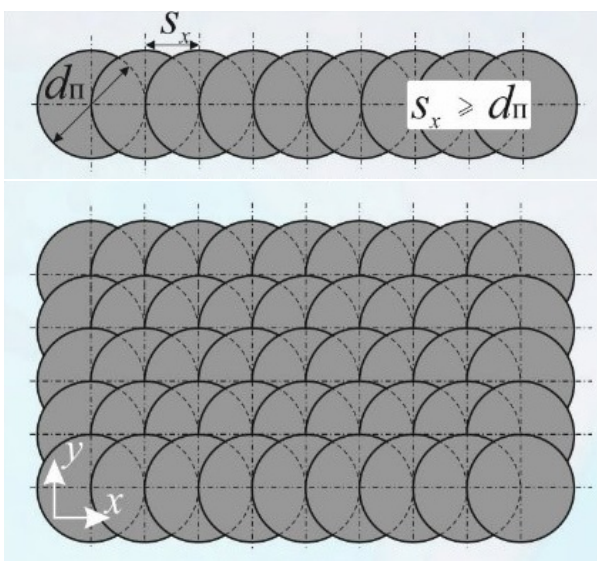

FiguRE 6. Scheme of linear and surface laying of spots for Laser shock Peening [5].

\section{MicRostrains AND CRYstallite SIZE}

Simultaneously with the measurement of the macroscopic residual stresses, determination of crystallite size and microstrains was provided using the Rietveld analysis. All results are demonstrated in [6] .

From the measured values is evident that crystallite size after thermal annealing and after laser machining increased, which is probably due to recrystallization during these treatments. A decrease of microstrains is observed after air abrasive machining when the yield point was overcome and the grain sizes increased. After stress tests by steel disc the largest crystallite size $\mathrm{Al}_{2} \mathrm{O}_{3}$ are observed, that could be again due to thermal relaxation and recrystallization of the surface.

\section{Conclusions}

Values of residual stresses of cutting ceramics $\mathrm{Al}_{2} \mathrm{O}_{3}+\mathrm{TiC}$ were analysed in two perpendicular directions. The influence of machining technologies to residual stresses was studied in both the phases.

Anisotropy and different values for the two phases during grinding by diamond disc were obtained, and 


\begin{tabular}{|c|c|c|c|c|c|c|c|}
\hline \multicolumn{4}{|c|}{$\mathrm{Al}_{2} \mathrm{O}_{3}$} & \multicolumn{4}{|c|}{$\mathrm{TiC}$} \\
\hline \multicolumn{4}{|c|}{ L direction $\mathrm{RS} \operatorname{Mn} K \alpha(0210)$} & \multicolumn{4}{|c|}{ L direction $\mathrm{RS} \operatorname{Cr} K \alpha(311)$} \\
\hline Sample & $\begin{array}{c}\sigma_{N} \\
{[\mathrm{MPa}]}\end{array}$ & $\begin{array}{c}\sigma_{S} \\
{[\mathrm{MPa}]}\end{array}$ & $\begin{array}{c}\text { FWHM } \\
{[2 \Theta]}\end{array}$ & Sample & $\begin{array}{c}\sigma_{N} \\
{[\mathrm{MPa}]}\end{array}$ & $\begin{array}{c}\sigma_{S} \\
{[\mathrm{MPa}]}\end{array}$ & $\begin{array}{c}\text { FWHM } \\
{[2 \Theta]}\end{array}$ \\
\hline 7 & -99 & 38 & 0.712 & 7 & -406 & 118 & 0.644 \\
\hline 8 & -149 & 42 & 0.733 & 8 & -363 & 74 & 0.691 \\
\hline 9 & -255 & 47 & 0.732 & 9 & -568 & 118 & 0.765 \\
\hline \multicolumn{4}{|c|}{$\mathrm{T}$ direction $\mathrm{RS} \operatorname{Mn} K \alpha(0210)$} & \multicolumn{4}{|c|}{$\mathrm{T}$ direction $\mathrm{RS} \operatorname{Cr} K \alpha(311)$} \\
\hline Sample & $\begin{array}{c}\sigma_{N} \\
{[\mathrm{MPa}]}\end{array}$ & $\begin{array}{c}\sigma_{S} \\
{[\mathrm{MPa}]}\end{array}$ & $\begin{array}{c}\text { FWHM } \\
{[2 \Theta]}\end{array}$ & Sample & $\begin{array}{c}\sigma_{N} \\
{[\mathrm{MPa}]}\end{array}$ & $\begin{array}{c}\sigma_{S} \\
{[\mathrm{MPa}]}\end{array}$ & $\begin{array}{c}\text { FWHM } \\
{[2 \Theta]}\end{array}$ \\
\hline 7 & -85 & 43 & 0.790 & 7 & -374 & 116 & 0.644 \\
\hline 8 & -166 & 50 & 0.752 & 8 & -364 & 88 & 0.689 \\
\hline 9 & -238 & 45 & 0.668 & 9 & -484 & 108 & 0.669 \\
\hline
\end{tabular}

TABLE 7. The values of normal $\left(\sigma_{N}\right)$ and shear $\left(\sigma_{S}\right)$ residual stresses after Water Jet Machining.

\begin{tabular}{|c|c|c|c|c|c|c|c|}
\hline \multicolumn{4}{|c|}{$\mathrm{Al}_{2} \mathrm{O}_{3}$} & \multicolumn{4}{|c|}{$\mathrm{TiC}$} \\
\hline \multicolumn{4}{|c|}{ L direction $\mathrm{RS} \operatorname{Mn} K \alpha(0210)$} & \multicolumn{4}{|c|}{ L direction $\mathrm{RS} \operatorname{Cr} K \alpha(311)$} \\
\hline Sample & $\begin{array}{c}\sigma_{N} \\
{[\mathrm{MPa}]}\end{array}$ & $\begin{array}{c}\sigma_{S} \\
{[\mathrm{MPa}]}\end{array}$ & $\begin{array}{c}\text { FWHM } \\
{[2 \Theta]}\end{array}$ & Sample & $\begin{array}{c}\sigma_{N} \\
{[\mathrm{MPa}]}\end{array}$ & $\begin{array}{c}\sigma_{S} \\
{[\mathrm{MPa}]}\end{array}$ & $\begin{array}{c}\text { FWHM } \\
{[2 \Theta]}\end{array}$ \\
\hline 10.1 & -53 & 31 & 0.731 & 10.1 & -318 & 111 & 0.594 \\
\hline 10.2 & 31 & 31 & 0.717 & 10.2 & -259 & 96 & 0.657 \\
\hline 10.3 & -29 & 23 & 0.757 & 10.3 & -200 & 106 & 0.637 \\
\hline 10.4 & -62 & 17 & 0.751 & 10.4 & -220 & 95 & 0.568 \\
\hline \multicolumn{4}{|c|}{$\mathrm{T}$ direction $\mathrm{RS} \operatorname{Mn} K \alpha(0210)$} & \multicolumn{4}{|c|}{$\overline{\mathrm{T}}$ direction $\mathrm{RS} \operatorname{Cr} K \alpha(311)$} \\
\hline Sample & $\begin{array}{c}\sigma_{N} \\
{[\mathrm{MPa}]}\end{array}$ & $\begin{array}{c}\sigma_{S} \\
{[\mathrm{MPa}]}\end{array}$ & $\begin{array}{c}\text { FWHM } \\
{[2 \Theta]}\end{array}$ & Sample & $\begin{array}{c}\sigma_{N} \\
{[\mathrm{MPa}]}\end{array}$ & $\begin{array}{c}\sigma_{S} \\
{[\mathrm{MPa}]}\end{array}$ & $\begin{array}{c}\text { FWHM } \\
{[2 \Theta]}\end{array}$ \\
\hline 10.1 & -155 & 9 & 0.856 & 10.1 & -509 & 148 & 0.619 \\
\hline 10.2 & -125 & 9 & 0.868 & 10.2 & -448 & 135 & 0.545 \\
\hline 10.3 & -71 & 42 & 0.737 & 10.3 & -367 & 135 & 0.543 \\
\hline 10.4 & -48 & 39 & 0.704 & 10.4 & -288 & 123 & 0.618 \\
\hline
\end{tabular}

TABLE 8. The values of normal $\left(\sigma_{N}\right)$ and shear $\left(\sigma_{S}\right)$ residual stresses after Laser Shock Peening.

\begin{tabular}{cc}
\hline Sample & $\begin{array}{c}\text { P, } \\
\text { Power } \\
{[\mathrm{W}]}\end{array}$ \\
\hline 10.1 & 2 \\
10.2 & 5 \\
10.3 & 10 \\
10.4 & 15 \\
\hline
\end{tabular}

TAble 9. Parameters of Laser Shock Peening. Pulse frequency $f=30 \mathrm{kHz}$, displacement $s_{x}=s_{y}=$ $40 \mu \mathrm{m}$.

the thermal relaxation of macroscopic residual stresses after thermal annealing was also measured.

For air abrasive cutting overcoming of the yield stress was found out with increasing the pressure to 2.5 MPa. Due to rotational movement during air abrasive machining and water jet machining the values of surface residual stresses are isotropic.

Samples machined by laser exhibit thermal relax-

\begin{tabular}{cc}
\hline & $\begin{array}{c}\mathrm{T}, \\
\text { Sample }\end{array}$ \\
& $\begin{array}{c}\text { Time of loading } \\
{[\mathrm{s}]}\end{array}$ \\
\hline 11.1 & 2 \\
11.2 & 6 \\
11.3 & 12 \\
\hline
\end{tabular}

TABle 10. Parameters of stress tests.

ation of residual stresses. At the same time, the found anisotropy of state of residual stresses is due to overlapping of laser-processed areas.

On the samples after the loading tests thermal relaxation of residual stresses was observed. It was shown that titancarbide is more sensitive to load than aluminium oxide. For more detailed information see [6].

\section{ACKNOWLEDGEMENTS}

This work was supported by grant Student Grant Competition CTU no. SGS16/246/OHK4/3T/14 and Grant Agency of the Czech Republic (no. 14-36566G). 


\begin{tabular}{|c|c|c|c|c|c|c|c|}
\hline \multicolumn{4}{|c|}{$\mathrm{Al}_{2} \mathrm{O}_{3}$} & \multicolumn{4}{|c|}{$\mathrm{TiC}$} \\
\hline \multicolumn{4}{|c|}{$\mathrm{L}$ direction $\mathrm{RS} \operatorname{Mn} K \alpha(0210)$} & \multicolumn{4}{|c|}{$\mathrm{L}$ direction $\mathrm{RS} \operatorname{Cr} K \alpha(311)$} \\
\hline Sample & $\begin{array}{c}\sigma_{N} \\
{[\mathrm{MPa}]}\end{array}$ & $\begin{array}{c}\sigma_{S} \\
{[\mathrm{MPa}]}\end{array}$ & $\begin{array}{c}\text { FWHM } \\
{[2 \Theta]}\end{array}$ & Sample & $\begin{array}{c}\sigma_{N} \\
{[\mathrm{MPa}]}\end{array}$ & $\begin{array}{c}\sigma_{S} \\
{[\mathrm{MPa}]}\end{array}$ & $\begin{array}{c}\text { FWHM } \\
{[2 \Theta]}\end{array}$ \\
\hline 11.1 & -42 & 27 & 0.693 & 11.1 & -453 & 64 & 0.655 \\
\hline 11.2 & 3 & 21 & 0.606 & 11.2 & -129 & 76 & 0.530 \\
\hline 11.3 & -78 & 40 & 0.596 & 11.3 & -242 & 49 & 0.577 \\
\hline \multicolumn{4}{|c|}{$\mathrm{T}$ direction $\mathrm{RS} \operatorname{Mn} K \alpha(0210)$} & \multicolumn{4}{|c|}{$\mathrm{T}$ direction $\mathrm{RS} \operatorname{Cr} K \alpha(311)$} \\
\hline Sample & $\begin{array}{c}\sigma_{N} \\
{[\mathrm{MPa}]}\end{array}$ & $\begin{array}{c}\sigma_{S} \\
{[\mathrm{MPa}]}\end{array}$ & $\begin{array}{c}\text { FWHM } \\
{[2 \Theta]}\end{array}$ & Sample & $\begin{array}{c}\sigma_{N} \\
{[\mathrm{MPa}]}\end{array}$ & $\begin{array}{c}\sigma_{S} \\
{[\mathrm{MPa}]}\end{array}$ & $\begin{array}{c}\text { FWHM } \\
{[2 \Theta]}\end{array}$ \\
\hline 11.1 & -145 & 17 & 0.612 & 11.1 & -348 & 95 & 0.580 \\
\hline 11.2 & -15 & 19 & 0.610 & 11.2 & -190 & 59 & 0.563 \\
\hline 11.3 & 47 & 24 & 0.649 & 11.3 & -240 & 66 & 0.446 \\
\hline
\end{tabular}

TABLE 11. The values of normal $\left(\sigma_{N}\right)$ and shear $\left(\sigma_{S}\right)$ residual stresses after stress testing.

\section{REFERENCES}

[1] R. Kumar, et al. Synthesis and characterization of $\mathrm{al}_{2} \mathrm{O}_{3}+$ tic nano-composite by spark plasma sintering. International Journal of Refractory Metals and Hard Materials 577:9-15, 2016.

[2] Z. Yin, et al. Friction and wear behaviors of $\mathrm{al}_{2} \mathrm{O}_{3}+$ tic micro-nano-composite ceramic sliding against metals and hard materials. International Journal of Refractory Metals and Hard Materials 577:9-15, 2016.
[3] A. Humár. Materiály pro řezné nástroje. First printing. MM publishing, 2008.

[4] C. B. Carter, M. G. Norton. Ceramic materials: science and engineering. Second edition. Springer Science and Business Media, 2013.

[5] M. University STANKIN. Materials for experimental measurement.

[6] J. Němeček. Studium reálné struktury oxidových řezných keramik. 